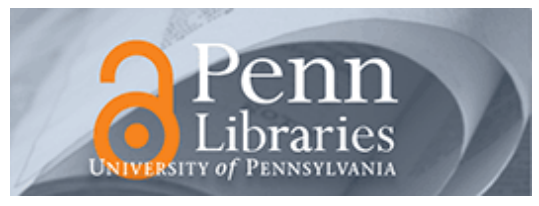

University of Pennsylvania

ScholarlyCommons

Marketing Papers

Wharton Faculty Research

October 1980

\title{
Advocacy as a Scientific Strategy: The Mitroff Myth
}

\author{
J. Scott Armstrong \\ University of Pennsylvania, armstrong@wharton.upenn.edu
}

Follow this and additional works at: https://repository.upenn.edu/marketing_papers

\section{Recommended Citation}

Armstrong, J. S. (1980). Advocacy as a Scientific Strategy: The Mitroff Myth. Retrieved from https://repository.upenn.edu/marketing_papers/116

Postprint version. Published in Academy of Management Review, Volume 5, Issue 4, October 1980, pages 509-511.

Publisher URL: http://www.aom.pace.edu/amr/

This paper is posted at ScholarlyCommons. https://repository.upenn.edu/marketing_papers/116

For more information, please contact repository@pobox.upenn.edu. 


\title{
Advocacy as a Scientific Strategy: The Mitroff Myth
}

\author{
Abstract \\ A committee created a fictitious author, Ian Mitroff, who published a paper that violated scientific \\ guidelines. The Mitroff paper recommended an advocacy strategy for scientific research; it said that \\ scientists should vigorously defend their initial hypothesis. I use the advocacy strategy to scientifically \\ prove that Mitroff does not exist.

\section{Comments} \\ Postprint version. Published in Academy of Management Review, Volume 5, Issue 4, October 1980, pages \\ 509-511. \\ Publisher URL: http://www.aom.pace.edu/amr/
}


[Reprinted from Academy of Management Review, 5 (1980), 509-511]

\title{
Advocacy as a Scientific Strategy: The Mitroff Myth
}

\author{
J. Scott Armstrong \\ Marketing Department, The Wharton School \\ University of Pennsylvania
}

A committee created a fictitious author, Ian Mitroff, who published a paper that violated scientific guidelines. The Mitroff paper recommended an advocacy strategy for scientific research; it said that scientists should vigorously defend their initial hypothesis. I use the advocacy strategy to scientifically prove that Mitroff does not exist.

In September 1971, in connection with the debate over the United States Anti-Ballistic Missile System, an ad hoc committee for the Operations Research Society of America [ORSA, 1971] published a set of guidelines for doing scientific research. The ORSA committee members were concerned that many people who claim to be scientists operate in violation of these guidelines. Their feelings could be summarized as follows: Most so-called scientists either do not understand or cannot bring themselves to follow the scientific method. They solve problems in a biased fashion just as non-scientists do. The result is that most of the scientific literature is pure garbage. Worse yet, the scientists cannot even recognize it as garbage. The committee felt that publication of the guidelines was unlikely to have a significant effect on the behavior of scientists. To give their report some impact, the committee tried to generate a controversy over the guidelines by publishing papers under the fictitious name of Ian Mitroff. (Mitroff is Russian slang for hoax.)

The purpose of "The Myth of Objectivity" [Mitroff, 1972] was to present guidelines on the proper use of the scientific method and then to violate these guidelines in an obvious fashion. The only constraint was that the paper should look as if it were a serious piece of work. Previous Mitroff papers had not been successful in drawing response because the violation of the guidelines had been less obvious. The only adverse reaction was by Litsios [1970] in response to Mitroff [1969].

"The Myth of Objectivity" was submitted for publication by the committee to demonstrate that unscientific papers are publishable. In fact, it was published by a reputable scientific journal, Management Science. Furthermore, the paper was accepted by readers as a serious piece of work, and Ian Mitroff was accepted as a real scientist. The reaction to the paper exceeded the expectations of the committee. It was widely read, and its mythical author received invitations to lecture at scientific institutions.

The ORSA committee was hastily convened to determine the next step. Here the accounts of what happened vary greatly. Although some members of the committee objected, a decision was made to perpetuate the hoax by hiring an actor to pose as Mitroff. Furthermore, the 
committee continued publishing articles under the pseudonym of Ian Mitroff (analogous to the Bourbaki case in which a number of French mathematicians published under the pseudonym of Nicolas Bourbaki for many years; that case is described in Halmos [1957]).

I was asked by one of the dissenting members of the committee (whose name I am not at liberty to disclose) to reveal the hoax. Although the project had reached the point that it was embarrassing to many people, the value of a hoax requires that it eventually be revealed.

\section{Analysis of "The Myth of Objectivity"}

"The Myth of Objectivity" described a study of over forty eminent physical scientists who were repeatedly interviewed in order to find out how they conducted scientific investigations. An attempt was made to identify the approach used by the most successful of these scientists.

Some of the paper's violations of the ORSA guidelines are described here (space does not permit a complete listing). The discussion parallels the guidelines as summarized on the first two pages of "The Myth of Objectivity." The italicized phrases are from the ORSA guidelines and the quotation marks refer to phrases used by Mitroff. The page numbers refer to Mitroff's paper.

The scientific method:

1. is open. Scientific papers should try to provide full and accurate disclosure of methods and data. This guideline was violated in the first paragraph of the paper. Mitroff not only failed to provide the necessary data, he refused: "I am not at liberty to disclose the full details of my study."

2. is self-correcting. Mitroff stated [p. B615] that "Objectivity results from the heated, intense, and biased confrontation and struggle between the 'somewhat' biased ideas of 'somewhat' biased individuals. That which survives the process is labeled 'objective' or scientifically true." In other words, an other-correcting process is a self-correcting process. But elsewhere [p. B614], Mitroff implied that the researcher should not give up his favored thesis "no matter how strong that negative evidence may appear at the time." It is difficult to imagine how a biased confrontation between closed minds could form the basis for an effective selfcorrecting process.

3. combines logic and empirical evidence. The basic logic of the Mitroff article was fallacious. Results from a descriptive study were used to make prescriptive statements. That is, arguments were presented to demonstrate that advocacy is used; the conclusion was then drawn that advocacy should be used. This conclusion does not follow logically from the premise. Faulty logic in the paper is also demonstrated by the following argument (paraphrased from page B616): If advocacy is important to scientific progress, then its absence is detrimental to scientific progress; therefore, advocacy is important to scientific progress. 
4. is objective. The lack of objectivity in Mitroff's article was highlighted by the use of emotional language, as in "if advocacy is indeed the rule rather than the exception, then the mythic concept of science and ORSA's guidelines are not just naive or innocuous, but downright dangerous" [p. B616].

These examples demonstrate that "The Myth of Objectivity" indeed violated the ORSA guidelines for scientific research.

\section{The Mitroff Myth: An Application of Advocacy}

The examples in the preceding section provide a brief description of the committee's attempt to violate the ORSA guidelines in their Mitroff article. Despite these violations, the paper was accepted by a reputable journal, and many readers believed that it was a serious article written by a real person.

The committee went to great lengths to create a scientist who would seem real - even to the extent of having "Mitroff" publish other papers [e.g., Mitroff, 1969, 1972]. Furthermore, there is someone who masquerades as Mitroff by answering mail and making guest appearances. In fact, I have met this person. (Obviously, I am not at liberty to reveal the true identity of this person.) In short, the committee created a highly plausible scientist, one who has the same attitudes and beliefs, as do many people who claim to be scientists.

This type of deception is apparently easy. Another committee [Naftulin et al., 1973] created a "Dr. Fox," who gave lectures at scientific meetings. No one was aware that he was a fake, even though he presented a meaningless paper.

It has been suggested by some people that Ian Mitroff actually does exist. Nothing could be further from the truth! Little evidence of his existence is available. The evidence that does purport to demonstrate his existence is hopelessly flawed by a lack of suitable controls. Reported sightings have been made by biased observers who failed to provide full disclosure of their methods and of the conditions under which their observations were made. These findings were not replicated by others in any systematic way. No quantitative analyses were performed and no reports were made on the reliability and validity of the sightings. Their methods provid ed no safeguards that would allow one to distinguish between an actual Mitroff and someone merely posing as a person named Mitroff. Nor is the evidence sufficient to distinguish the real Ian Mitroff from a different person with the same name. The methods are no better than those used in the sightings of unidentified flying objects. In summary, I found no evidence that would prove beyond a doubt that he does exist. Furthermore, it should be apparent that no real person would write such a patently absurd article.

The fact that Mitroff does not exist has thus been shown scientifically. The proper scientific approach is for different advocates to publish their opposing viewpoints. They should do this in the strongest terms possible. I have made the case that Mitroff does not exist. Anyone of the opposite opinion should try to publish that viewpoint. It is then up to the scientific community to decide whether Ian Mitroff really does exist or whether he was created by the 
ORSA committee. (Incidentally, my informant told me that the ORSA committee will vigorously deny having created Ian Mitroff. They can be expected, for example, to ask the person who is currently claiming to be Mitroff to reply to this article and to claim that Ian Mitroff is truly a person.) I am sure, in the long run, the scientific community will agree with me that Mitroff does not exist. As for me, I will never give up my favored hypothesis that Mitroff does not exist, no matter how strong the negative evidence may appear at any time.

\section{Reader's Guide}

In response to popular demand, a reader's guide is provided here: The introduction is designed to gain reader interest. The section entitled "Analysis . .." used the ORSA guidelines to analyze the Mitroff paper; there are serious problems with the Mitroff paper. The discussion on the existence of Mitroff uses the advocacy strategy in its extreme form. The last sentence of the text was drawn from the Mitroff paper. If you find advocacy as objectionable as I do you might be interested in a more objective analysis of the problem, using the method of multiple hypotheses to examine alternatives to advocacy [Armstrong, 1979].

\section{References}

Armstrong, J.S., “Advocacy and objectivity in science," Management Science, 1979, 25, 423428.

Halmos, R., “Nicolas Bourbaki,” Scientific American, 1957, 196, 88-99.

Litsios, S., "Critique of Professor Ian I. Mitroff's Fundamental issues in the simulation of human behavior: A case study in the strategy of behavioral science," Management Science, 1970, 17, B115-B116. "Reply to Dr. Socrates Litsios," by Ian 1. Mitroff, pp. B116-B118.

Mitroff, I., "Fundamental issues in the simulation of human behavior: A case study of the strategy of behavioral science," Management Science, 1969, 15, B635-B649.

Mitroff, I., "The myth of objectivity, or why science needs a new psychology of science," Management Science, 1972, 18, B613-B618.

Mitroff, I., "The mythology of methodology: An essay on the nature of a feeling science," Theory \& Decision, 1972, 2, 274-290.

Naftulin, D.H.; Ware, E., Jr.: \& Donnelly, FA. “The Doctor Fox lecture: A paradigm of educational seduction," Journal of Medical Education, 1973, 48, 630-635.

ORSA Committee, "Guidelines for the practice of operations research," Operations Research, 1971, 19, 1123-1148. 